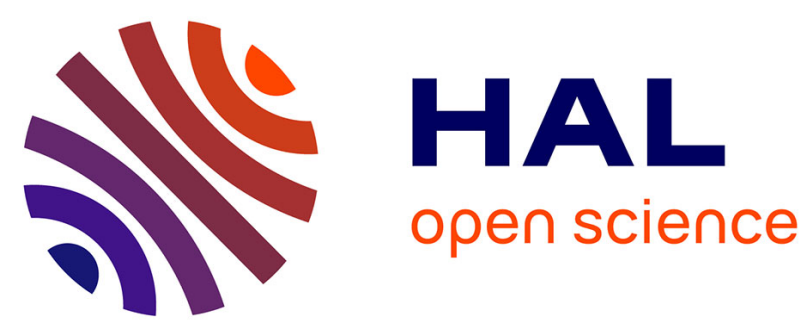

\title{
Extended biomass allometric equations for large mangrove trees from terrestrial LiDAR data
}

Adewole A. Olagoke, Christophe Proisy, Jean-Baptiste Féret, Elodie

Blanchard, François Fromard, Ulf Mehlig, Moirah Machado de Menezes, Valdenira Ferreira dos Santos, Olagoke Adewole, Uta Berger

\section{To cite this version:}

Adewole A. Olagoke, Christophe Proisy, Jean-Baptiste Féret, Elodie Blanchard, François Fromard, et al.. Extended biomass allometric equations for large mangrove trees from terrestrial LiDAR data. Trees - Structure and Function, 2016, 10.1007/s00468-015-1334-9 . ird-01242762

HAL Id: ird-01242762

https://hal.ird.fr/ird-01242762

Submitted on 23 Dec 2015

HAL is a multi-disciplinary open access archive for the deposit and dissemination of scientific research documents, whether they are published or not. The documents may come from teaching and research institutions in France or abroad, or from public or private research centers.
L'archive ouverte pluridisciplinaire HAL, est destinée au dépôt et à la diffusion de documents scientifiques de niveau recherche, publiés ou non, émanant des établissements d'enseignement et de recherche français ou étrangers, des laboratoires publics ou privés. 


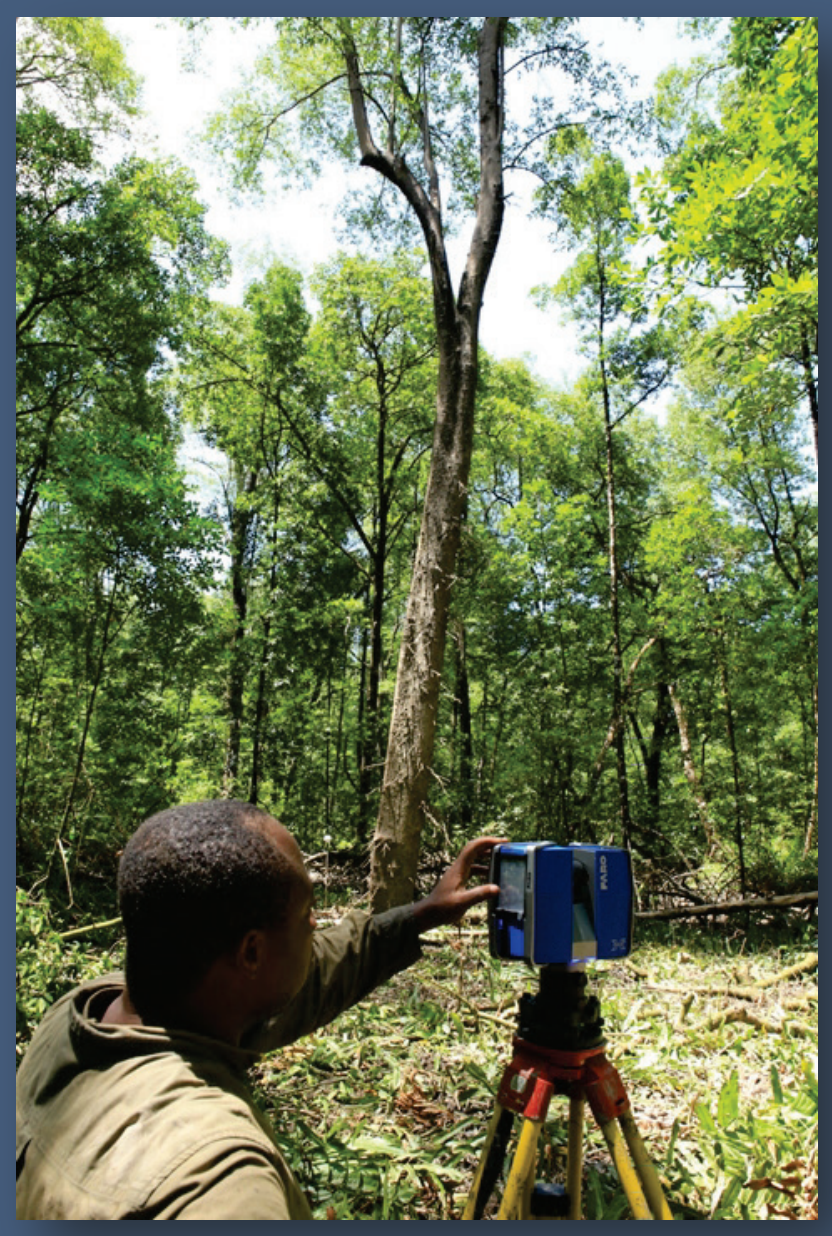

\section{Extended biomass allometric equations for large mangrove trees from terrestrial LiDAR data}

Olagoke Adewole, Christophe Proisy, Jean-Baptiste Féret, Elodie Blanchard, François Fromard, Ulf Mehlig, Moirah Machado de Menezes, Valdenira Ferreira dos Santos, Uta Berger

Manuscript published in Trees: Structure and Function

https://dx.doi.org/10.1007/s00468-015-1334-9 


\section{Extended biomass allometric equations for large mangrove trees from terrestrial LiDAR data}

Olagoke Adewole ${ }^{1,2,3^{*}}$, Christophe Proisy ${ }^{2}$, Jean-Baptiste Féret ${ }^{4}$, Elodie Blanchard ${ }^{2}$, François Fromard ${ }^{5,6}$, Ulf Mehlig $^{7}$, Moirah Machado de Menezes ${ }^{7}$, Valdenira Ferreira dos Santos ${ }^{8}$, Uta Berger ${ }^{1}$

\footnotetext{
${ }^{1}$ Institute of Forest Growth and Computer Sciences, Technische Universität, Dresden, Germany adewole.olagoke@tudresden.de, uta.berger@tu-dresden.de

${ }^{2}$ IRD, UMR-AMAP, 34000 Montpellier, France christophe.proisy@ird.fr, elodie.blanchard@ird.fr

${ }^{3}$ Institut des sciences et industries du vivant et de l'environnement (AgroParisTech), Campus d'Agropolis International, 648 rue Jean-François Breton, 34093 Montpellier, France

${ }^{4}$ IRSTEA, UMR-TETIS, 500 rue J.F. Breton, 34093 Montpellier Cedex 5, France jb.feret@teledetection.fr

${ }^{5}$ Université de Toulouse; INP, UPS; EcoLab, 118 Route de Narbonne, 31062 Toulouse, France

${ }^{6}$ CNRS; EcoLab; 31062 Toulouse, France francois.fromard@univ-tlse3.fr ;

7Instituto de Estudos Costeiros, Universidade Federal do Pará, Campus de Bragança, Brazil ulf@ufpa.br, moirah@ufpa.br

${ }^{8}$ Instituto de Pesquisas Científicas e Tecnológicas do Estado do Amapá (IEPA), Macapá, Brazil valdeniraferreira@gmail.com
}

Key Message: We estimated aboveground biomass of large mangrove trees from terrestrial Lidar measurements. This makes the first attempt to extend mangrove biomass equations validity range to trunk diameter reaching $125 \mathrm{~cm}$.

\section{Abstract}

Accurately determining biomass of large trees is crucial for reliable biomass analyses in most tropical forests, but most allometric models calibration are deficient in large trees data. This issue is a major concern for highbiomass mangrove forests, especially when their role in the ecosystem carbon storage is considered. As an alternative to the fastidious cutting and weighing measurement approach, we explored a non-destructive terrestrial laser scanning approach to estimate the aboveground biomass of large mangroves (diameters reaching up to $125 \mathrm{~cm}$ ). Because of buttresses in large trees, we propose a pixel-based analysis of the composite 2D flattened images, obtained from the successive thin segments of stem point-cloud data to estimate wood volume. Branches were considered as successive best-fitted primitive of conical frustums. The product of wood volume and height-decreasing wood density yielded biomass estimates. This approach was tested on 36 A. germinans trees in French Guiana, considering available biomass models from the same region as references. Our biomass estimates reached ca. $90 \%$ accuracy and a correlation of 0.99 with reference biomass values. Based on the results, new tree biomass model, which had $\mathrm{R}^{2}$ of 0.99 and RSE of $87.6 \mathrm{~kg}$ of dry matter. This terrestrial LiDAR-based approach allows the estimates of large tree biomass to be tractable, and opens new opportunities to improve biomass estimates of tall mangroves. The method could also be tested and applied to other tree species.

Keywords: Aboveground biomass; Coastal blue carbon; French Guiana; Mangrove; Terrestrial LiDAR; Tree allometry

Introduction

Recent studies have highlighted the importance of large trees as keystone ecological elements (Lindenmayer et al. 2012; Lutz et al. 2013) in forest ecosystems. The significance extends beyond the characteristic contribution to regeneration as mother trees and the provision of food and shelter for many living organisms, because they also represent the principal structures shaping ecosystem biomass productivity and recurrent forest dynamics (Slik et al. 2013). In terms of wood volume, biomass, and carbon stocks, they dominate the forest structure and this may explain variations in biomass distribution across forest landscapes (Bastin et al. 2015a). Thus, an accurate estimation of the biomass of large trees is crucial for obtaining reliable estimates of the total biomass in such forests.

One key challenge is that the biomass data of large tropical tree are generally scarce (e.g. only ca. $7 \%$ of the available pantropical tree biomass dataset, Chave et al. 2014). This is also the case for the tall mangroves that 
grow in the equatorial region. Although the species diversity of mangroves is low compared with rainforests, the variability in the tree structure of Avicennia species, for example, is higher. Avicennia trees may exhibit a wide range of growth forms, from small to large/ tall trees, depending on the habitat condition. Considering this variation in tree structure, available models may actually fall short in their predictive power for out-of-sample application. This situation also appears a limitation on the extent to which the existing general pantropical biomass allometric models can be applied to mangrove trees, without significant bias in the resulting estimates.

Meanwhile, there is a growing interest in attaining highly precise estimates of biomass and carbon stock of tropical forests (Gibbs et al. 2007; Pistorius 2012), including mangroves, as in the case of the blue carbon projects. This necessitates the refinement of the available methods, like the commonly used allometric models, and the development of unbiased protocols for biomass measurement. Currently, the available biomass models for mangrove trees (Komiyama et al. 2008) only cover a range of small - medium sized trees $(D B H \leq 50$ $\mathrm{cm})$ and are deficient in respect of large trees. Collecting data, using the conventional cutting and weighing method, to validate mangrove biomass models for large trees is however difficult in the tidal environment.

The terrestrial laser scanning (TLS), also known as terrestrial LiDAR (light detection and ranging), offers a remote sensing technology that allows capturing the high resolution three-dimensional (3D) structure of trees with relatively low time and labour requirements. Earlier applications in the forest sciences and ecological studies include the description of forest structural parameters (Strahler et al. 2008), assessment of canopy metrics and gaps (Bayer et al. 2013; Coops et al. 2007; Hilker et al. 2010), individual tree volume and biomass estimation (e.g. Calders et al. 2015; Dassot et al. 2012), to the application in estimating leaf area and foliage properties (Béland et al. 2014; Huang and Pretzsch 2010). Interestingly, various approaches have tested satisfactorily in the estimation of individual tree volume and biomass from TLS point cloud data: from the use of tree features extraction (Kankare et al. 2013; Pueschel et al. 2013), shape reconstruction and primitive fittings (Raumonen et al. 2013; Yu et al. 2013) to voxelization (Hauglin et al. 2013).

Some automatic techniques have been proposed for reconstructing and modelling of tree structure and topology (Akerblom et al. 2015; Hackenberg et al. 2014; Raumonen et al. 2013), and they achieved notably good results with regular, cylindrical shaped tree trunks, and mostly in leaf-off conditions. Since such methods are based on segmental geometric primitive fits, irregularities in the shape of large tropical trees like mangroves remain challenging for direct application of such automatic tree reconstruction. For irregular trunk shapes, we presume that automatic techniques may require a combination with (semi-)manual interactive steps. All the same, the application of TLS in the study of mangrove species remains largely unexplored; the only pilot attempt was limited to mangrove trees with $D B H<43 \mathrm{~cm}$ (Feliciano et al. 2014). In the present study, our aims were (1) to describe and evaluate the performance of a simple TLS-based method for estimating the wood volume and biomass of large mangrove trees, and (2) to propose revised allometric models for the widespread mangrove tree species Avicennia germinans (L.) L. with a validation domain extended to very large trees.

\section{Methods}

\section{Study area}

The study was performed in French Guiana (hereafter referred to as FG) where mangroves stretch along a 320 $\mathrm{km}$ coastline (Appendix 1), to cover an approximate area of 70,000 ha. This coast can be considered as pristine, because there are still no extensive industrial activities, and aquaculture and tree exploitation are not present. It is subjected primarily to sediment dispersal from the Amazon River (Baltzer et al. 2004). The spatiotemporal distribution of mangroves is controlled by a succession of rapid and acute erosion and accretion phases caused by the drifting of giant mud-banks to the northwest of the coastline (Anthony et al. 2010).

The mangrove forests encompass new colonization on the freshly consolidated mud-banks up to mature forests located several kilometers inland at the limit of tidal influence. In this area, mangroves are unaffected by coastal instability (Anthony et al. 2010) and this allows trees to reach their largest potential stature. Fromard et al. (1998) described the different mangrove forest types of FG; $A$. germinans (L.) L. is represented from pioneer to old-growth forest, spanning a wide range of growth stages. These growth stages are patchily distributed across the coastal landscape with clusters of young trees, sometimes in close vicinity to decaying stands (Proisy et al. 2007). 
The sampling locations were selected in order to capture data from trees distributed over a wide $D B H$ range. This $D B H$ range was distributed in three distinct forest stands. (Appendix 1). First, a mixed old-growth Avicennia-Rhizophora forest stand near Petit Cayenne $10 \mathrm{~km}$ upstream of the Cayenne river, with a stand density of 504 trees per hectare, total basal area of 26.2 $\mathrm{m}^{2}$.ha ${ }^{-1}$ and $A$. germinans trees reaching a mean $D B H$ of $56.2 \mathrm{~cm}$. The second stand, located at about $3 \mathrm{~km}$ from the actual mangrove shoreline along Guatemala road, was made up of small-medium size and scattered large A. germinans trees. The tree density in this stand was 3733 trees per hectare with a total basal area of 25.5 $\mathrm{m}^{2}$.ha ${ }^{-1}$, and average $D B H$ of $15 \mathrm{~cm}$. The third stand was an even-aged $A$. germinans forest located $6 \mathrm{~km}$ backward of the mangrove seafront in the Sinnamary region. This stand contained mainly $A$. germinans in a density of 1132 trees per hectare with basal area totalling $21.8 \mathrm{~m}^{2}$.ha $\mathrm{h}^{-1}$.

\section{Essential features of Avicennia germinans (L.) $L$.}

In this study, we employed $A$. germinans as a proxy species to test a new method for estimating the biomass of mangrove trees using TLS data. This is a keystone species and the most dominant mangrove species on the FG coast (Fromard et al. 1998, Fromard et al. 2004). A. germinans trees vary greatly in size and growth form. The species grows from low-scrubby (ca. 0.4-1.5 $\mathrm{m}$ tall) in the sub-optimal habitats (Vogt et al. 2014) to large trees approaching $42 \mathrm{~m}$ height and 125 $\mathrm{cm}$ diameter in favorable and stable growth conditions, as found in some regions of FG. Trunks are roughly cylindrical to slightly angled or even canaliculated and may develop buttresses and short fascicles of aerial roots. The trees reiterate to produce coppice shoots when the main stem is damaged, resulting in frequently contorted stem development.

\section{Existing biomass allometric models for A. germinans}

Fromard et al. (1998) developed biomass allometric models for aboveground biomass $(A G B)$ of mangrove trees in FG. The models for A. germinans followed a power function, with two coefficients (Table 1). They were calibrated using data obtained from small to medium-sized trees with $D B H$ of $4-42 \mathrm{~cm}$ and corresponding $A G B$ between 4.8 and $1543.7 \mathrm{~kg}$ of dry matter, respectively.
Table 1 Reference models from Fromard et al. (1998) for $A$. germinans trees ( $\mathrm{DBH} \leq 42 \mathrm{~cm}$ ) based on power function of the tree diameter $\left(\alpha \cdot \mathrm{DBH}^{\beta}\right)$

\begin{tabular}{ccccc}
\hline Model ID & $\boldsymbol{\alpha}$ & $\boldsymbol{\beta}$ & $\mathbf{R}^{\mathbf{2}}$ & $\mathbf{n}$ \\
\hline $\begin{array}{c}A G B \text { tree biomass } \\
\left(A G B_{\text {ref }}\right)\end{array}$ & 0.14 & 2.44 & 0.97 & 25 \\
$\begin{array}{c}\text { Trunk biomass } \\
\left(B T R_{\text {ref }}\right)\end{array}$ & 0.07 & 2.59 & 0.97 & 25 \\
$\begin{array}{c}\text { Branch biomass } \\
\left(B B R_{\text {ref }}\right)\end{array}$ & 0.03 & 2.33 & 0.97 & 25 \\
$\begin{array}{c}\text { Leaf biomass } \\
\left(\text { BLeaf }_{\text {ref }}\right)\end{array}$ & 0.04 & 1.77 & 0.91 & 25 \\
\hline
\end{tabular}

The coefficients $\alpha$ (intercept) and $\beta$ (slope) are constant parameters, and $\mathrm{n}$ is the number of sample trees.

These models conformed to the biomass allometric model developed for the same species in Guadeloupe (Imbert and Rollet 1989). Other mangrove biomass models applicable to $A$. germinans are the two generic equations developed by Chave et al. (2005) and Komiyama et al. (2005), which were also calibrated with trees $D B H<60 \mathrm{~cm}$. An independent dataset obtained by direct cutting and weighing of sample trees (Fromard et al. 1998) at the same study locations as ours jointly with the predicted biomass estimates of currently sampled trees, using the allometric models of Fromard et al. (1998), were used for reference to evaluate the TLSbased biomass values and new models presented in this study.

\section{Wood density (WD) measurements at different heights}

In most studies of allometric relationships, the $W D$ is estimated at breast height. To our knowledge, no WD measurements have been reported at different heights along the main axis for $A$. germinans so far. Thus, we initiated an experiment that involved coring $A$. germinans trees at different heights in various mangrove regions throughout FG. We climbed 20 trees $(10<D B H<110 \mathrm{~cm})$ and used hand-powered drills to extract 52 samples. The wood core samples measured $4.3 \mathrm{~mm}$ in diameter with lengths of $2-13 \mathrm{~cm}$ over bark. The core heights along the stem axis ranged from $0.3 \mathrm{~m}$ for all trees up to $23 \mathrm{~m}$ for tall trees, corresponding to diameters varying from $4.8 \mathrm{~cm}$, at the top of small trees, up to $110 \mathrm{~cm}$ at the base of large trees. All core samples were dried at a constant temperature of $105{ }^{\circ} \mathrm{C}$ for several days until constant mass, and subsequently weighted in relation to wood volume to obtain $W D$ as dry weight. High variability in the WD was observed at heights below $10 \mathrm{~m}$, and also around the breast height. 
The distribution of wood density along the main stem vs. sampling height and diameter was fitted using a linear mixed effects (LME) model, with the individual tree as random factor. This analysis was based on WD data from the outer wood core samples, since the outer $W D$ values are known to strongly correlate to the $W D$ values from any point along the radial spectrum, without a significant bias (Bastin et al. 2015b).

\section{TLS measurements and data processing}

The TLS measurements used in this study were collected with a FARO Focus ${ }^{3 D}$ X330 device between August and September 2014. The instrument operates using a $1.55 \mu \mathrm{m}$ class 1 laser signal. The distance between the scanner and the object is determined by analyzing the shift in the wavelength of the return beam. The device can scan objects at a distance of up to
$330 \mathrm{~m}$; and with an accuracy of $<0.25 \mathrm{~mm}$ for dark objects at a distance of $25 \mathrm{~m}$. The vertical and horizontal fields of view are $300^{\circ}$ and $360^{\circ}$, respectively. Several scanning resolutions can be used for collecting point cloud data from the focal surface. However, we chose the second finest scanning configuration able to achieve complete scanning at about $20 \mathrm{~min}$ with a distance accuracy reaching $\pm 3 \mathrm{~mm}$ over a horizontal range of $90^{\circ}$ as the finest scan required more than 1 hour for an accuracy slightly improved to $\pm 2 \mathrm{~mm}$ over the same distance. A flowchart that illustrates the procedure for data acquisition and subsequent processing is presented in Fig. 1. More detailed methodical descriptions are provided in the subsequent sections.

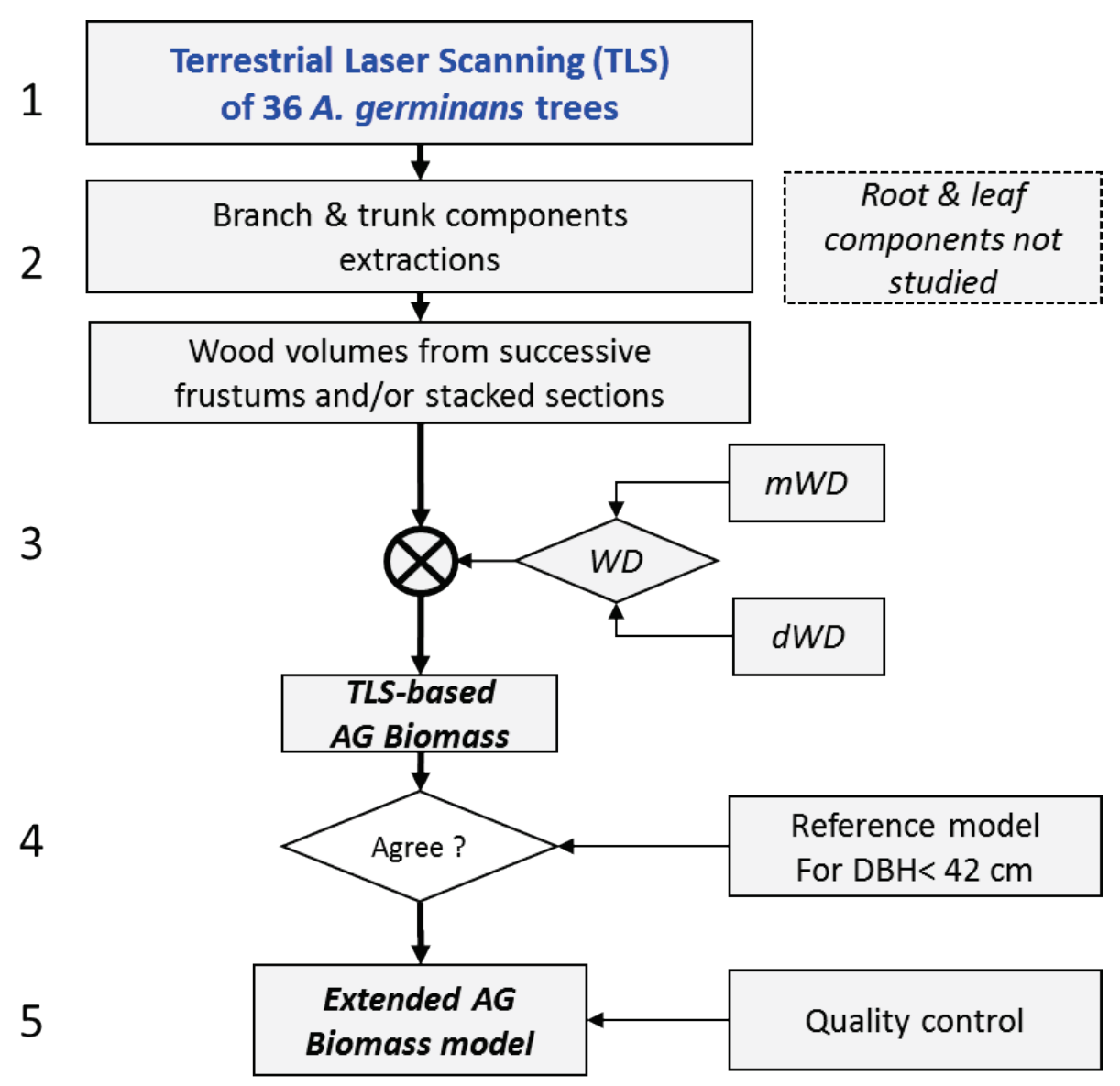

Fig. 1 Scheme of procedure for TLS data acquisition and processing in mangrove tree biomass estimation. AG = aboveground, $W D=$ wood density, $m W D=$ mean $W D$ value at tree $D B H$, and $d W D=$ decreasing value of $W D$ with height along the stem axis

\section{Mangrove tree scanning}

The number of trees selected for each scanning operation ranged from a single (large) tree to a group of six individual (small to medium-sized) trees. Before placing the instrument, several viewpoints were identified for TLS placement around selected 
individual(s), and subsequently distribution of the target spheres (reference objects to aid merging/ alignment of multiscans). This was a crucial step because it directly affected the quality of the 3D description of the focal mangrove tree(s). In this experiment, five white target spheres were positioned in the foreground and background surrounding the focal trees at different heights ranging from $0-2 \mathrm{~m}$ using stands made of metal rods and pipes, at a minimum distance of ca. $3 \mathrm{~m}$ from the tree base (Appendix 2). The TLS instrument was mounted on a sturdy tripod stand, with additional support from reinforced metal frames (ca. $60 \mathrm{~cm}$ long) embedded in the muddy sediment. One can adapt the length of these support metal frames as required, until adequate stability is reached before mounting the LiDAR system. The number of scan positions was selected as a function of the horizontal and vertical projections of the target trees. To minimize the chance of occlusions or missing parts in the 3D tree structure, it was essential to scan large individual trees with buttresses from at least 5 viewpoints at high scanning resolution. Summary descriptions of the sample trees are presented in Table 2.

\section{Extraction of trunk and branches from point-cloud data}

The TLS data processing comprised merging of multiple scans, filtering or removal of background vegetation, and generating point clouds for individual trees of interest. This process was conducted using the FARO SCENE 5.2 software. The process took from ca. 1 - 12 working hours to complete one large tree, depending on its structure. The main trunk and primary branches (in the case of large trees) were manually separated, and the 3D coordinates of the point cloud were exported for subsequent processing. The computation routine for wood volume and biomass was implemented in MATLAB. For control, we also fitted successive geometric primitives on point cloud data of trunks and branches ( $>4 \mathrm{~cm}$ at the branch base) using the least squares method.

\section{Computation of the trunk and branch volumes}

Two volume computation procedures were performed for the trunks: (1) volume estimation of successive bestfitted geometric shapes (primitive fitting), and (2) an automatic pixel count on 2D flattened projection of segmented thin trunk sections. The trunk volume estimates from the composite primitive shapes fitted on the selected trunks served for the validation of the pixel-based analysis. The determination of the volume of tree branches was restricted to manual primitive shape fittings in this study due to computational complexity.

\section{Stem volume estimation by primitive fitting}

For each tree, sets of conical frustums were extracted that corresponded to the main trunk and each branch. The diameters at the base $(D b)$ and the top $(D t)$, and the height $(H c)$ of each solid shape were recorded. Thereafter, the geometrical volume ( $V c$ for trunk and $V c b$ for branches) of each primitive shape was estimated as a truncated cone, as given by equation 1 .

$V c_{i}=\frac{\pi \cdot H c_{i}}{12} \cdot\left(D b_{i}^{2}+D b_{i} \cdot D t_{i}+D t_{i}^{2}\right)$

All of the $V c$ values in a trunk were summed to obtain the trunk volume. The addition of the component $V c b$ of each branch yielded the branch volume.

\section{Trunk volume estimation with the pixel-based method}

We implemented a program routine that decomposed 3D trunk shapes into successive thin sections (Fig. 2a-c). The height of each section to the ground level was recorded. These sections were converted into twodimensional (2D) binary images to obtain their flattened plan projections. Different segmentation heights (section thickness), ranging from $1 \mathrm{~cm}$ to $1 \mathrm{~m}$, were tested to find a trade-off between complete shape outline and gaps in the 2D plan. When open shapes occurred in the point cloud (due to occlusion on trunk part during scanning), they were filled automatically by fitting a simple convex envelope around the missing region. The area covered by the boundary of the section was then divided into a grid of $1 \mathrm{~cm}^{2}$ pixels. The number of pixels in the flattened image of each section was summed to obtain its surface area, and the volume was obtained as the product of the surface area and its thickness, and the trunk volume was obtained as the total stacked constituent sections. These trunk volume estimates were compared with the volume obtained from primitive fittings (described above) to validate the pixel-based method. 
Table 2 Descriptive metrics of sample trees selected for the TLS experiment

\begin{tabular}{|c|c|c|c|c|c|c|}
\hline Site ID & $\begin{array}{l}\text { Location } \\
\text { coordinates }\end{array}$ & Forest type & $\begin{array}{c}\text { No. of } \\
\text { trees }\end{array}$ & Tree ID & $D B H(\mathrm{~cm})$ & Total height (m) \\
\hline \multirow[t]{17}{*}{ Guatemala } & \multirow{17}{*}{$\begin{array}{l}5.07 \mathrm{~N} \\
52.54 \mathrm{~W}\end{array}$} & \multirow{17}{*}{$\begin{array}{c}\text { Small - medium size } \\
\text { A. germinans stands } \\
\text { with uneven ages }\end{array}$} & \multirow[t]{17}{*}{17} & GUA1 & 13.4 & 14.8 \\
\hline & & & & GUA2 & 15.8 & 17.2 \\
\hline & & & & GUA3 & 16.0 & 21.0 \\
\hline & & & & GUA4 & 16.0 & 20.1 \\
\hline & & & & GUA5 & 16.1 & 18.5 \\
\hline & & & & GUA6 & 17.6 & 21.8 \\
\hline & & & & GUA7 & 17.9 & 21.6 \\
\hline & & & & GUA8 & 18.7 & 20.3 \\
\hline & & & & GUA9 & 20.9 & 23.8 \\
\hline & & & & GUA10 & 22.7 & 20.4 \\
\hline & & & & GUA11 & 24.1 & 23.0 \\
\hline & & & & GUA12 & 26.0 & 21.3 \\
\hline & & & & GUA13 & 28.0 & 24.1 \\
\hline & & & & GUA14 & 28.5 & 22.3 \\
\hline & & & & GUA15 & 32.1 & 21.1 \\
\hline & & & & GUA16 & 50.0 & 18.4 \\
\hline & & & & GUA17 & 54.0 & 14.7 \\
\hline \multirow[t]{6}{*}{ Sinnamary } & \multirow{6}{*}{$\begin{array}{l}5.41 \mathrm{~N} \\
52.96 \mathrm{~W}\end{array}$} & \multirow{6}{*}{$\begin{array}{l}\text { Medium size } A \text {. } \\
\text { germinans stand } \\
\text { with similar ages }\end{array}$} & \multirow[t]{6}{*}{6} & SIN1 & 26.8 & 23.8 \\
\hline & & & & SIN2 & 33.5 & 29.7 \\
\hline & & & & SIN3 & 35.3 & 31.5 \\
\hline & & & & SIN4 & 35.0 & 29.7 \\
\hline & & & & SIN5 & 35.7 & 31.2 \\
\hline & & & & SIN6 & 44.9 & 33.4 \\
\hline \multirow{13}{*}{$\begin{array}{l}\text { Petit } \\
\text { Cayenne }\end{array}$} & \multirow{13}{*}{$\begin{array}{l}4.86 \mathrm{~N} \\
52.40 \mathrm{~W}\end{array}$} & \multirow{13}{*}{$\begin{array}{l}\text { Mixed old-growth } \\
\text { Avicennia and }\end{array}$} & \multirow[t]{13}{*}{13} & CAY1 & 47.8 & 34.0 \\
\hline & & & & CAY2 & 54.6 & 36.5 \\
\hline & & & & CAY3 & 56.4 & 35.3 \\
\hline & & & & CAY4 & 58.5 & 32.1 \\
\hline & & & & CAY5 & 64.0 & 32.5 \\
\hline & & & & CAY6 & 69.2 & 34.1 \\
\hline & & & & CAY7 & 70.5 & 34.0 \\
\hline & & & & CAY8 & 81.0 & 37.9 \\
\hline & & & & CAY9 & 91.6 & 36.1 \\
\hline & & & & CAY10 & 93.5 & 38.2 \\
\hline & & & & CAY11 & 94.0 & 36.4 \\
\hline & & & & CAY12 & 99.7 & 37.9 \\
\hline & & & & CAY13 & 124.5 & 41.3 \\
\hline
\end{tabular}

Biomass estimation from TLS-derived wood volume

Conversion of stem volume to biomass
In this study, we systematically obtained two biomass estimates: the first used a mean WD derived from our wood density sampling; and the second employed a decreasing WD relative to height along the stem axis 
derived from the respective linear mixed-effects model. In the latter case, we interpolated the height WD model to obtain specific WD at each section height by reference to the bottom of the tree. The biomass estimates for each of the trunk (BTR $\left.\mathrm{TLS}_{\mathrm{TL}}\right)$ and the branch $\left(B_{B R R_{T L S}}\right)$ components were obtained as the sum of the products of each section volume and the corresponding WD. The sum of the branch and trunk biomass of each tree provided its TLS-derived aboveground woody biomass (AGBW ${ }_{\text {TLS }}$ ). The leaf biomass was only considered in this study as a proportional relation following the model of Fromard et al. (1998) in Table 1, although it constituted an insignificant share of the AGB estimates.
Evaluation of TLS biomass estimates for trees DBH $<42$ $\mathrm{cm}$

We applied a cross-validation procedure to evaluate the accuracy of the TLS-derived trunk volume and biomass estimates of trees within the $D B H$ range of the reference data (Fromard et al. 1998). We calculated the root mean squared error (RMSE) and the accuracy using equations 2 and 3 , respectively:

$$
\begin{aligned}
& R M S E=\sqrt{\frac{\sum_{i=1}^{n}\left(F F_{i}-T L S_{i}\right)^{2}}{n},} \\
& \% R M S E=100 \cdot \frac{R M S E}{\text { mean }(F F)},
\end{aligned}
$$

where $F F_{i}$ denotes the reference values based on Fromard et al. (1998), TLS is the corresponding TLSderived estimate, and $n$ is the number of trees.
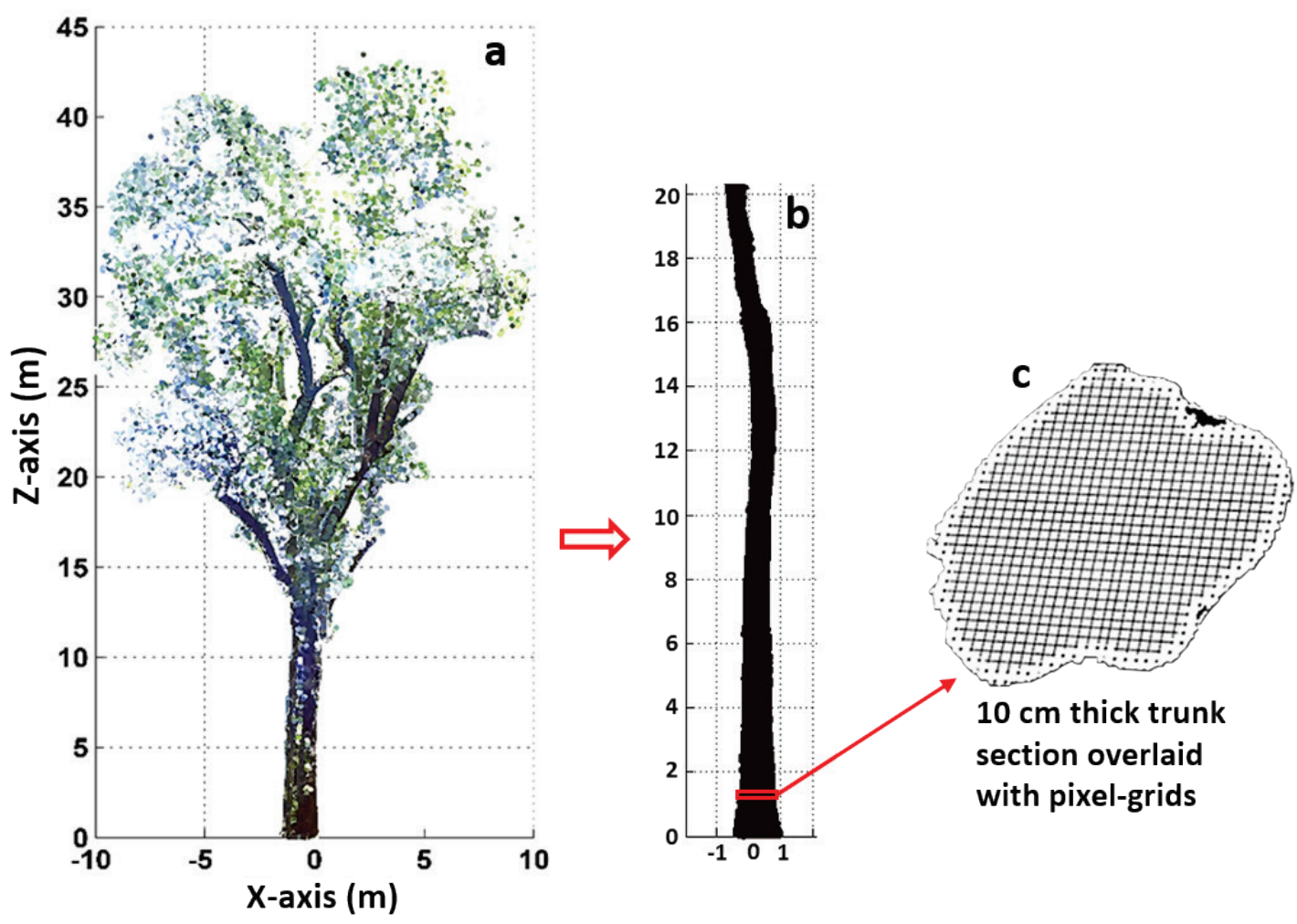

Fig. 2 Trunk segmentation and sectioning for stem volume computation. a) Typical view of a large mangrove tree. b) A trunk with $D B H=93.5 \mathrm{~cm}$. c) Typical flattened projection of a trunk section extracted at a height of $1.3 \mathrm{~m}$

\section{Fitting of allometric models using TLS-derived biomass data}

\section{Model calibration}

We employed TLS-derived data for calibrating easily applicable biomass allometric models. Based on tree diameter-biomass relationship of $A$. germinans, we fitted a new non-linear $A G B$ model with $D B H$ as the predictive variable using a maximum likelihood regression approach (M1, equation 4). The coefficients $\alpha$ and $\beta$ are parameters that characterized the new biomass models we obtained. As suggested by Chave et al. (2005) and Komiyama et al. (2005), we considered 
other models (M2-M4) that incorporated WD (denoted as $\rho$ in the allometric equations) and/or tree height $(H)$, as given by equations $5-7$ :

$\mathrm{M} 1: A G B=\alpha \cdot D B H^{\beta}+\varepsilon$,

$\mathrm{M} 2: A G B=\alpha \cdot \rho D B H^{\beta}+\varepsilon$,

M3: $A G B=\alpha \cdot\left(D B H^{2} H\right)^{\beta}+\varepsilon$,

M4: $A G B=\alpha \cdot \rho\left(D B H^{2} H\right)^{\beta}+\varepsilon$,

where $\varepsilon$ is the model error, which considers factors that may explain the difference in biomass between two trees with the same DBH and $\mathrm{H}$ dimensions. The branch (BBR.M) and trunk (BTR.M) models were fitted according to the model formulated in M1. All of the variables in these models were considered as logarithmic transformed variables to eliminate heteroscedasticity. To obtain biomass values by backtransformation, we applied the correction factor (CF) described by Sprugel (1983), which relies on the residual standard error (RSE) of the models, as given in equation 8 , thereby adjusting for the systematic bias associated with log-transformations of data.

$C F=\exp \left(\frac{R S E^{2}}{2}\right)$

\section{Evaluation of the biomass models}

A thorough validation of a new model normally requires the use of independent empirical datasets (Vanclay and Skovsgaard 1997). However, due to the relatively small sample size and paucity of separate validation datasets, we decided to employ goodness-of-fit statistics, Akaike's information criterion (AIC) for multi-model inference, and graphical analysis to assess the performances of the new models in comparison to the previous models produced by Fromard et al. (1998). All of the model fitting procedures and statistical evaluation were performed using MATLAB.

\section{Results}

\section{Height-dependent wood density}

$W D$ values ranged from 595 to $790 \mathrm{~kg} \mathrm{~m}^{-3}$ (Fig. 3) for trees over a DBH range of $10.4-110 \mathrm{~cm}$, with a mean value of $728.7 \pm 8.91 \mathrm{~kg} \mathrm{~m}^{-3}$ around the breast height.

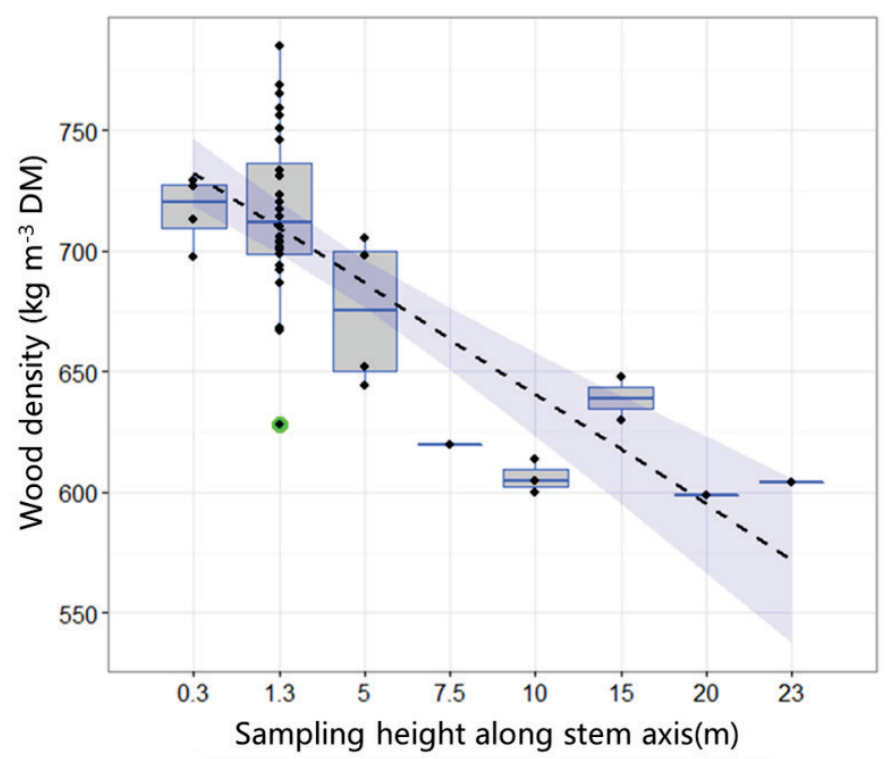

Fig. 3 Decreasing wood density at different heights along the stem axis: black dots denote the wood density values obtained from various tree samples; the green dot was consider an outlier; and the dashed line shows the linear model with a $95 \%$ confidence interval in blue

The LME model fitted for WD as a function of sample height and tree $D B H$, with the individual tree as random factor, demonstrated a decreasing trend along the stem axis. From the tree base to the top, each increase the sampling height resulted in a $0.7 \%$ decrease in the basal mean $W D$ value of $731.5 \pm 17.2 \mathrm{~kg} \mathrm{~m}^{-3}$. The inclusion of a measure of individual tree $D B H$ in the model resulted in ca. $0.08 \%$ increase in the predicted $(P=0.076)$. Thus, individual tree effect was not a significant factor in the total effects found in the distribution of wood density along the stem axis.

\section{Accuracy of pixel-based trunk volume estimation from TLS data}

Based on the performance test of the pixel-based method, the best results were achieved at a trunk section height of $10 \mathrm{~cm}$ during volume computation. These trunk volume estimates were compared with the geometric volume based on successive conical frustums for the analyzed trees (Fig. 4a). The RMSE between these two methods reached $6.7 \%$ of the mean value for 18 trees with no pronounced buttresses. The linear fit $\left(R^{2}=0.99\right)$ of the trunk volume estimates nearly overlaid the one-to-one line for the small, almost straight bole trees (Fig. 4a). Higher volume estimates were obtained from trees with more pronounced buttresses, with the RMSE value increased to $16.7 \%$ of the mean value and the $R^{2}$ decreased to 0.96 for larger 
trees (Fig. 4b). Overall, the pixel-based method produced trunk volume with an accuracy of ca. $90 \%$.

\section{Accuracy of TLS-based tree volume-to-biomass conversion}

The two specific $W D$ values were combined with the pixel-based trunk volume estimates to produce biomass of trees in the diameter range of the reference data. The mean value of $W D$ yielded a mean deviation of $16.5 \%$ (dry matter) compared with the reference biomass values for tree $D B H<42 \mathrm{~cm}$. The $d W D$ values lowered the mean deviation of the TLS-derived trunk biomass to $6.7 \%$ for the trees analysed in this study. Overall, the $d W D$-based biomass estimates strongly correlated with the reference values $(R=0.99)$, where the RMSE was $41.23 \mathrm{~kg}(14.21 \%)$ for the trunk biomass, $48.6 \mathrm{~kg} \mathrm{(13.6 \% )}$ for the aboveground woody components, and $48.5 \mathrm{~kg}$ (13.5\%) for the total $A G B$ (Fig. $5 \mathrm{a}-\mathrm{c}$ ), with biomass values ranging from ca. 70 to 900 $\mathrm{kg}$ (dry matter).

\section{Aboveground woody biomass of large A. germinans trees}

The sum of the TLS-derived branch and trunk biomass yielded the aboveground woody biomass of large trees. These values ranged from $1242 \mathrm{~kg}$ for a tree with a $D B H$ of $44.9 \mathrm{~cm}$ to $17,367 \mathrm{~kg}$ for a tree with a $D B H$ of 124.5 $\mathrm{cm}$. The branch biomass composition was almost uniform in small to medium-sized trees, i.e., 15-20\% of the tree biomass. For large trees, the branch biomass varied from ca. $20 \%$ to almost $50 \%$ of the tree $A G B$ in some cases.

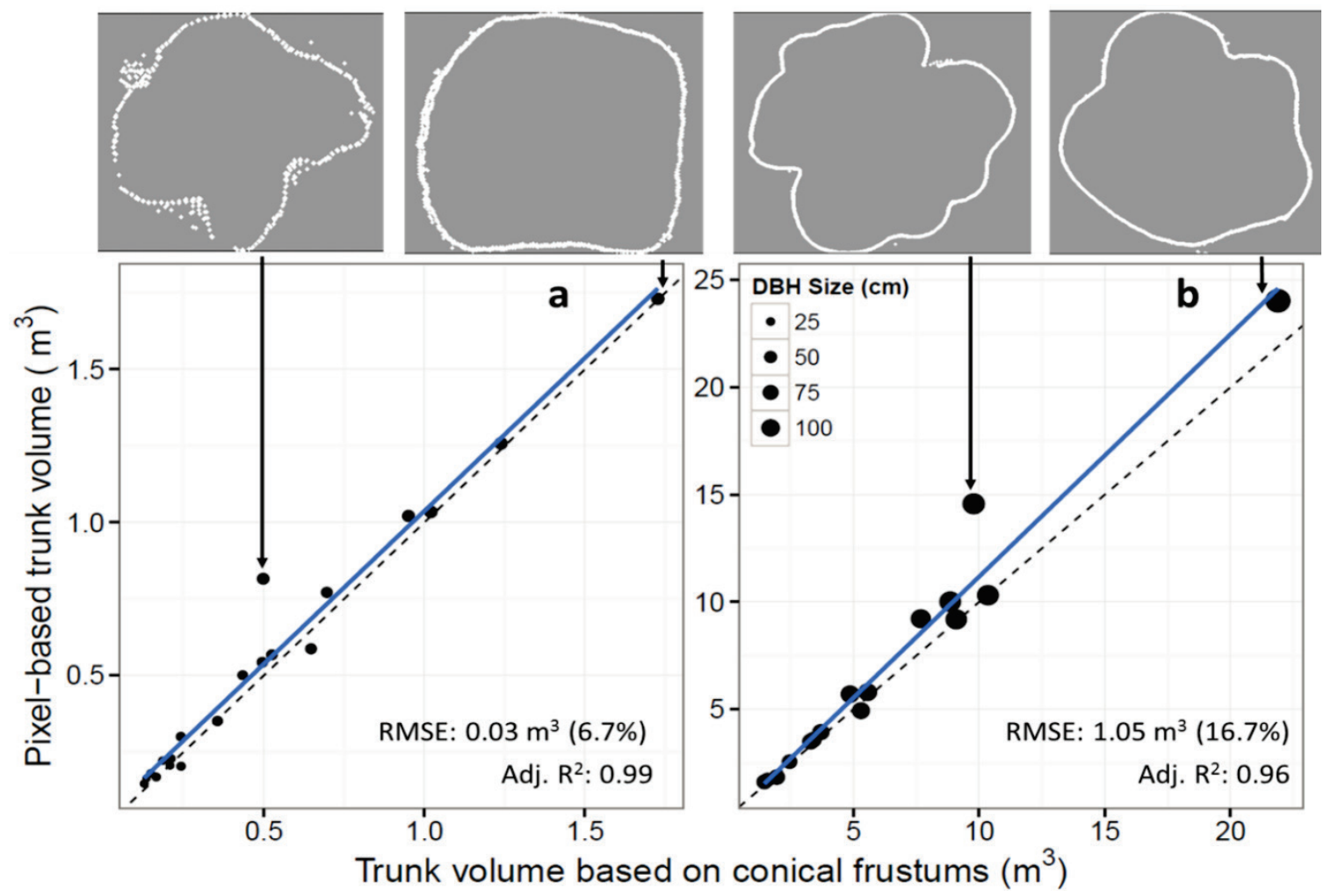

Fig. 4 Comparison of the trunk volumes estimated using the automatic pixel-based analysis of TLS data and the successive trunkfitted conical frustums for trees with $D B H<42 \mathrm{~cm} \mathrm{(a)} \mathrm{and}>42 \mathrm{~cm}$ (b). Outline of girth form of typical trunks are shown above in white with a grey background (arrows 1-4). The dashed line depicts a one-to-one relationship and the blue solid line corresponds to linear fit.

\section{Revised allometric models of A. germinans trees}

Using the new TLS-derived tree biomass and the available tree weight dataset, revised allometric models' parameters were proposed (Table 3 ). For the tree branch biomass (BBR.M), we obtained a model with the same intercept coefficient $(\alpha=0.03)$ as the reference model $\left(B B R_{\text {ref }}\right)$. Meanwhile, the model parameter $\beta$ and $R^{2}$ changed from 2.33 and 0.90 to 2.41 and 0.98 , respectively. The curve describing BBR.M clearly shifted upward for trees larger than the 
diameter range of $B B R_{\text {ref }}$ (Fig. 6a), indicating that the $B B R_{\text {ref }}$ underestimated the branch biomass of large trees. Our model for trunk biomass (BTR.M) was characterized by the model parameters $\alpha=0.11$ and $\beta=$ 2.46, which yielded a clear power curve deflection below the reference model (Fig. 6b). The $R^{2}$ also increased from 0.95 in the reference model $\left(B T R_{\text {ref }}\right)$ to 0.99 in the BTR.M. We obtained the best fit for a total $A G B$ (M1) model, which has $D B H$ as an explanatory variable (Table 3, Fig. 6c). The model clearly had different parameters, where $\mathrm{R}^{2}=0.99$ and corrected AIC were significantly lower compared with the reference model $\left(A G B_{\text {ref }}\right)$, but the corresponding residual standard error (RSE) only decreased by $1.2 \mathrm{~kg}(1.4 \%)$. With the exception of $M 2$, which is similar to $M 1$ in terms of model parameter and statistical attributes, M3 and M4 models with additional variable(s) (tree height and wood density) yielded higher residual standard errors compared with the $A G B_{\text {ref. }}$.

\section{Discussion}

In this study, we evaluated the possible use of TLS for estimating the $A G B$ of large mangrove trees ( $A$. germinans) to facilitate the development of improved, non-destructive measurement procedures and to achieve higher precision in allometric models.

\section{Accuracy of the TLS-derived mangrove tree biomass}

The results of the TLS-based biomass estimates reliably compare to the tree biomass weighed in the field for
$D B H<42 \mathrm{~cm}$. In particular, the estimates for the small to medium-sized trees had an accuracy of near $90 \%$ and they were highly correlated $(R=0.99)$ with the reference biomass. Interestingly, the accuracy of results produced using our simplified TLS data analysis achieved a comparable accuracy with results reported in previous studies (e.g., Raumonen et al. 2013, Calders et al. 2015). That the presence of buttresses in trees (Nogueira et al. 2006) may influence the overall accuracy of the TLS-derived biomass estimates justified the consideration for a pixel-based analysis adopted in this study. This approach respects the real shape of buttressed trees, making it particularly suitable for biomass measurement in large mangroves trees where basal protuberance are present.

Additionally, the careful selection of thickness for trunk sections in the segmentation process, as well as the consideration for the $W D$ variations along the stem axis during the biomass conversion contributed to a high precision of the TLS-derived biomass estimates. Notwithstanding, the approach that dwells on primitive shape fitting may be sufficient when trees are near perfect shaped cylinder or conical forms, as is with the case of small and medium sized trees. Overall, it is possible that the TLS-based measurement might insignificantly underestimate the actual tree biomass, especially for the crown biomass where the omission of fine twigs may likely occur.

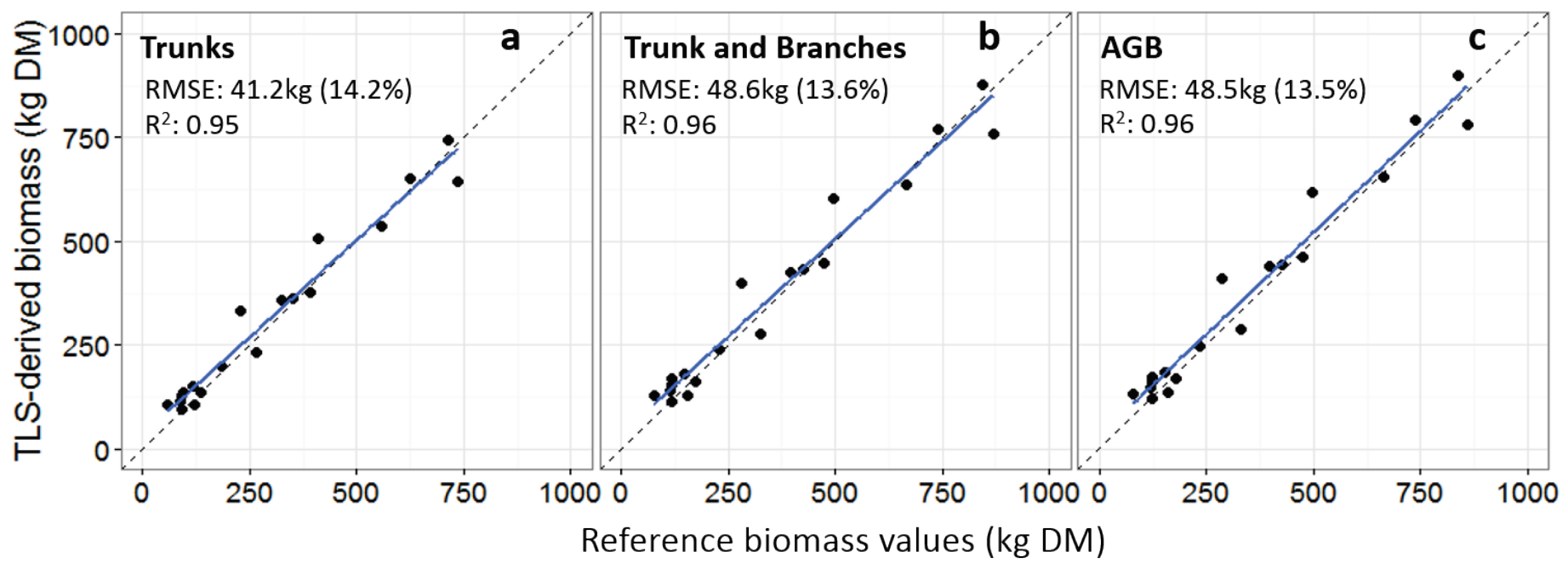

Fig. 5 Comparison of the TLS method relative to the estimates to the reference values for the trunk $D B H<42 \mathrm{~cm}(\mathrm{a})$, trunk and branches (b), and total biomass estimates (c). The dots correspond to the biomass values of the sample trees (cf. Fromard et al. 1998), the dashed line is a 1:1 relationship, and the blue solid line indicates the linear fit 
Table 3 Descriptions of the revised allometric models and associated statistical parameters

\begin{tabular}{|c|c|c|c|c|c|c|c|c|}
\hline Model ID & Model Form & $\begin{array}{c}D B H \\
\text { range } \\
\text { (cm) }\end{array}$ & $\begin{array}{l}\text { Number } \\
\text { of trees }\end{array}$ & $\alpha$ & $\beta$ & $R S E(k g)$ & $R^{2}$ & $A I C$ \\
\hline \multicolumn{9}{|l|}{ Branch } \\
\hline \multicolumn{9}{|l|}{ Models } \\
\hline$B B R_{\text {ref }}$ & $\alpha . D B H^{\beta}$ & $4-42$ & 25 & 0.03 & 2.33 & 65.4 & 0.90 & 56.36 \\
\hline BBR.M & & $4-125$ & 60 & 0.03 & 2.41 & 54.7 & 0.98 & 40.14 \\
\hline \multicolumn{9}{|c|}{ Trunk Models } \\
\hline$B T R_{\text {ref }}$ & $\alpha . D B H^{\beta}$ & $4-42$ & 25 & 0.07 & 2.59 & 122.6 & 0.95 & 30.08 \\
\hline BTR.M & & $4-125$ & 60 & 0.11 & 2.46 & 60.9 & 0.99 & 27.44 \\
\hline \multicolumn{9}{|c|}{ AGB Models } \\
\hline$A G B_{\text {ref }}$ & $\alpha . D B H^{\beta}$ & $4-42$ & 25 & 0.14 & 2.44 & 88.6 & 0.97 & 12.3 \\
\hline M1 & & $4-125$ & 60 & 0.16 & 2.42 & 87.4 & 0.99 & -3.86 \\
\hline $\mathrm{M} 2$ & $\alpha . \rho D B H^{\beta}$ & $4-125$ & 60 & 0.23 & 2.41 & 87.9 & 0.99 & -3.82 \\
\hline M3 & $\alpha\left(D B H^{2} H\right)^{\beta}$ & $4-125$ & 60 & 0.072 & 0.91 & 118.5 & 0.99 & 2.76 \\
\hline M4 & $\alpha\left(\rho D B H^{2} H\right)^{\beta}$ & $4-125$ & 60 & 0.099 & 0.91 & 117.5 & 0.99 & 2.57 \\
\hline
\end{tabular}

*AGB = aboveground biomass, $H$ height, $\rho$ wood density, $\alpha$ and $\beta$ coefficients, RSE residual standard error of estimates, AIC corrected Akaike's information criterion, i.e., a measure of a model's relative quality (the lowest AIC describes the best model), the BBR.M, BTR.M, M1-M4 are models extended to large trees and the $B B R_{\text {ref, }} B T R_{\text {ref }}$ and $A G B_{\text {ref }}$ are the reference models.

\section{Modelling mangrove tree biomass with TLS-derived data}

Given the significance of large-diameter trees in allometric models, the new sets of biomass equations obtained in this study, which extend to very large trees, should improve biomass analyses of mangrove forests. The models do not yield significantly different predictions; model M1 where only $D B H$ was used as an explanatory variable was shown to produce the best results according to the evaluation parameters. The TLSbased allometric models yielded new model parameters with higher predictive power, especially for the aboveground tree components of large trees.

It should be noted that the overestimation of the trunks of large trees in relation to the reference models was complemented by the corresponding underestimation from the branch model in the total $A G B$ estimates, with the new model yielding only slightly lower $A G B$ estimates for trees $D B H>42 \mathrm{~cm}$. Contrary to our expectations, the current results thus suggest that the reference model presents considerably good estimates for the total $A G B$, even for the very large trees.

The distinction in the behaviour of our models for the branch and trunk biomass and the reference models can be explained by the variations in the pattern of biomass partitioning in the aboveground tree components beyond the $D B H$ range of the reference models.
Fromard et al. (1998) confirmed that the small-medium size trees used to produce their models mostly had allocated the largest share of the $A G B$ to their trunks, which was also demonstrated in our current study.

The trees in these growth stages usually exhibit continuous growth in height and consistent natural pruning with no pronounced crown size. This growth pattern is likely related to survival strategies for fastgrowing trees in competitive growing conditions. Later, trees will reach approach asymptotically a height where only secondary growth in the tree girth and the crown development continue, and large trees may prioritize biomass distribution to the branches on the assumption of as a means for canopy space filling and to ensure mechanical stability. Since the allocation of biomass to different tree components is subject to environmental effects, we suggest that considering the plasticity of tree morphology in mangrove allometric models may greatly facilitate improved biomass prediction in a range of environmental conditions. Indeed, Peters et al. (2014) have demonstrated such an environment-related plasticity in a mechanistic approach in their BETTINA model. This and similar models can be parameterized with TLS-derived data to achieve a framework for accurate biomass analyses from natural scrubby to tall mangrove forests.

In this study, the allometric model where mean WD was incorporated slightly increased the residual error of the biomass predictions compared with the base model. 
Since the $W D$ varies with the individual tree size, but also at different heights within an individual $A$. germinans tree, it is possible that the use of global or site-specific mean values may result in more biased estimates. Nevertheless, this factor has greater importance when parameterizing allometric models for species-specific comparisons among different sites or in multispecies applications (Chave et al. 2005, Chave et al. 2014). In addition, the inclusion of tree height as an additional variable in the current allometric models incurred higher residual error to biomass estimates. More so that this variable is not always available and not easy to measure, we suggest that the allometric model based only on the $D B H$ is sufficient for estimating the biomass of $A$. germinans trees under optimal growth conditions.

\section{Challenges affecting the wider application of TLS in mangrove studies}

The TLS provides an attractive, indirect method for the estimation of forest biomass, but several challenges need to be addressed to maximize its usability in mangrove studies. Deflection of tree crowns by the wind occurred during measurements in some of our scanning operations, especially with small to mediumsized trees. Thus, avoiding scanning during windy periods may reduce the likelihood of errors in such conditions.

In addition, large mangrove trees occasionally have hollow trunks due to rotting of the heartwood. This may lead to significant errors in the biomass estimates obtained for large trees based on indirect nondestructive measurements (Nogueira et al. 2006). However, it is questionable whether it is, in a real world scenario, feasible to reliably capture the necessary information on hollow trees, even from conventional destructive sampling. Without knowledge of the average volume of the cavities in the different tree size classes and the respective probability of their occurrence, subsequent estimation of biomass from regression models relying on $D B H$ surveys will consequently fail, regardless of the calibration technique applied. Advances in the application of ultrasonic tomography (Brancheriau et al. 2008) and Resistograph measurements (Rinn et al. 1996) demonstrate non-destructive detection of volume of cavities in trees. Integrating these measurements with the TLS-based method in the future could address the uncertainty caused by the possible presence of tree cavities.

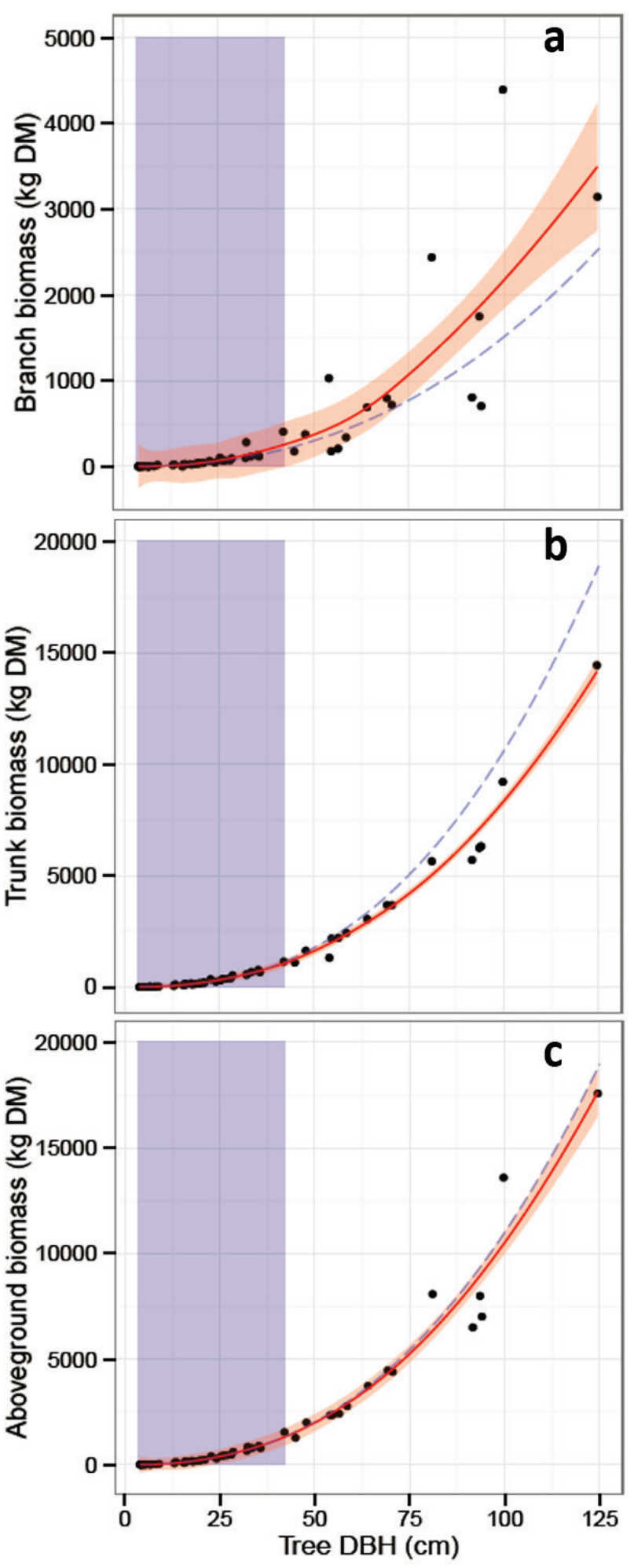

Fig. 6 Comparison of the TLS-based biomass functions and the reference models for $A$. germinans. The branch (a), trunk (b), and total $A G B$ (c) are distinguished. The red line and the surrounding shade represent the new model and confidence interval. The dashed line is the prediction from the reference model, calibrated over the $D B H$ range in the shaded area 
Meanwhile, in the current study, we have carefully avoided hollow trunks by a systematic restriction of sampling to physically sound trees (i.e., without signs of crack or rotten parts).

By considering the individual architecture of trees, our proposed TLS-based method could have wide applicability to other mangrove species. The work of Feliciano et al. (2014) already demonstrated a workaround for TLS application to Rhizhophora species, considering the prop roots as toroidal objects to estimate their volumes and biomass. Their approach and the one presented here are fundamental towards ensuring the wider applicability of the TLS method for the studies on mangrove tree architecture and ecosystem functioning. The approaches could also be supported by tree architecture studies, which are scarce for mangroves at present, for example, for species developing prop roots, or aerial appendages.
Conclusively, the TLS data analysis provides a viable substitute for the destructive biomass measurement and allows estimates of large mangrove trees to be tractable. This opens new research opportunities in mangroves studies with respect to tree architecture, biomass productivity and ecosystem functioning. Our current allometric models may facilitate accurate determinations of the biomass for the aboveground parts with potential benefit to the success of the coastal blue carbon projects for conservation of mangrove forests. To advance the TLS method to other mangrove forests, a fully automatic procedure for volume and biomass estimation is desirable for use in the natural scrubby to tall mangrove forests, and this may require further refinement of our current procedure for TLS data collection and processing.

Acknowledgements: This research was conducted under the framework of the MANGWATCH project funded by the French Centre National de la Recherche Scientifique (CNRS) research program "Incubator for interdisciplinary research projects in French Guiana." Adewole Olagoke received doctoral fellowship from the European Commission under the Erasmus Mundus Joint Doctorate programme, Forest and Nature for Society (FONASO), and travel grants from the CNRS and Technische Universität Dresden Graduate Academy (Germany). Jean-Baptiste Féret is grateful to the French Centre National d'Etudes Spatiales (CNES) for supporting a postdoctoral fellowship. We thank the TOSCA program of the CNES for providing a grant to develop a 3D mock-up of mangrove trees within the framework of the BIOMASS mission preparation. This study is dedicated to the memory of Michael Guéroult, our friend and colleague, who passed away all too soon. We greatly appreciate the two anonymous reviewers for their insightful and constructive comments.

\section{References}

Åkerblom M., Raumonen P., Kaasalainen M. \& Casella E. (2015) Analysis of Geometric Primitives in Quantitative Structure Models of Tree Stems. Remote Sens. 7, 4581-4603. Anthony EJ, Gardel A, Gratiot N, Proisy C, Allison MA, Dolique $F$, Fromard F (2010) The Amazon-influenced muddy coast of South America: A review of mud-bank-shoreline interactions Earth-Science Reviews 103:99-121

Baltzer F, Allison M, Fromard F (2004) Material exchange between the continental shelf and mangrove-fringed coasts with special reference to the Amazon-Guianas coast Marine Geology 208:115-126 doi:10.1016/j.margeo.2004.04.024

Bastin JF et al. (2015a) Seeing Central African forests through their largest trees Scientific Reports 5:13156

Bastin JF et al. (2015b) Wood Specific Gravity Variations and Biomass of Central African Tree Species: The Simple Choice of the Outer Wood PLoS One 10:e0142146 doi:10.1371/journal.pone.0142146

Bayer D, Seifert S, Pretzsch H (2013) Structural crown properties of Norway spruce (Picea abies [L.] Karst.) and European beech (Fagus sylvatica [L.]) in mixed versus pure stands revealed by terrestrial laser scanning Trees 27:10351047 doi:10.1007/s00468-013-0854-4
Béland $M$, Baldocchi DD, Widlowski J-L, Fournier RA, Verstraete MM (2014) On seeing the wood from the leaves and the role of voxel size in determining leaf area distribution of forests with terrestrial LiDAR Agricultural and Forest Meteorology 184:82-97

Brancheriau L, Lasaygues P, Debieu E, Lefebvre JP (2008) Ultrasonic tomography of green wood using a non-parametric imaging algorithm with reflected waves Annals of Forest Science 65:712-712 doi:10.1051/forest:200851

Calders K et al. (2015) Nondestructive estimates of aboveground biomass using terrestrial laser scanning Methods in Ecology and Evolution 6:198-208

Chave J et al. (2005) Tree allometry and improved estimation of carbon stocks and balance in tropical forests Oecologia 145:87-99 doi:10.1007/s00442-0050100-x

Chave J et al. (2014) Improved allometric models to estimate the aboveground biomass of tropical trees Glob Chang Biol 20:3177-3190 doi:10.1111/gcb.12629

Coops N, Hilker T, Wulder M, St-Onge B, Newnham G, Siggins A, Trofymow JA (2007) Estimating canopy structure of Douglas-fir forest stands from discrete-return LiDAR Trees 21:295-310 doi:10.1007/s00468-006-0119-6 
Dassot $M$, Colin A, Santenoise $P$, Fournier $M$, Constant $T$ (2012) Terrestrial laser scanning for measuring the solid wood volume, including branches, of adult standing trees in the forest environment Computers and Electronics in Agriculture 89:86-93 doi:10.1016/j.compag.2012.08.005

Feliciano EA, Wdowinski S, Potts MD (2014) Assessing Mangrove Above-Ground Biomass and Structure using Terrestrial Laser Scanning: A Case Study in the Everglades National Park Wetlands 34:955-968

Fromard F, Puig H, Mougin E, Marty G, Betoulle JL, Cadamuro $L$ (1998) Structure, above-ground biomass and dynamics of mangrove ecosystems: new data from French Guiana Oecologia 115:39-53 doi:10.1007/s004420050489

Fromard F, Vega C, Proisy C (2004) Half a century of dynamic coastal change affecting mangrove shorelines of French Guiana. A case study based on remote sensing data analyses and field surveys Marine Geology 208:265-280 doi:10.1016/j.margeo.2004.04.018

Gibbs HK, Brown S, O Niles JO, Foley JA (2007) Monitoring and estimating tropical forest carbon stocks: making REDD a reality Environmental Research Letters 2:1-13

Hackenberg J, Wassenberg M, Spiecker H, Sun D (2015) Non Destructive Method for Biomass Prediction Combining TLS Derived Tree Volume and Wood Density Forests 6:1274-1300 Hauglin M, Astrup R, Gobakken T, Næsset E (2013) Estimating single-tree branch biomass of Norway spruce with terrestrial laser scanning using voxel-based and crown dimension features Scandinavian Journal of Forest Research 28:456-469 Hilker T, van Leeuwen M, Coops N, Wulder M, Newnham G, Jupp DB, Culvenor D (2010) Comparing canopy metrics derived from terrestrial and airborne laser scanning in a Douglas-fir dominated forest stand Trees 24:819-832 Huang P, Pretzsch H (2010) Using terrestrial laser scanner for estimating leaf areas of individual trees in a conifer forest Trees 24:609-619 doi:10.1007/s00468-010-0431-z

Imbert D, Rollet B (1989) Phytomasse aerienne et production primaire dans la mangrove du Grand Cul-de-Sac Marin (Guadeloupe, Antilles francaises) Bulletin d'Ecologie 20:27-39 Kankare V et al. (2013) Individual tree biomass estimation using terrestrial laser scanning ISPRS Journal of Photogrammetry and Remote Sensing 75:64-75 doi:http://dx.doi.org/10.1016/j.isprsjprs.2012.10.003

Komiyama A, Ong JE, Poungparn S (2008) Allometry, biomass, and productivity of mangrove forests: A review Aquatic Botany 89:128-137 doi:10.1016/j.aquabot.2007.12.006

Komiyama A, Poungparn S, Kato S (2005) Common allometric equations for estimating the tree weight of mangroves Journal of Tropical Ecology 21:471-477 doi:10.1017/s0266467405002476

Lindenmayer DB, Laurance WF, Franklin JF (2012) Global Decline in Large Old Trees Science 338:1305-1306 doi:10.1126/science.1231070

Lutz JA, Larson AJ, Freund JA, Swanson ME, Bible KJ (2013) The Importance of Large-Diameter Trees to Forest Structural Heterogeneity PLoS ONE 8:e82784
Nogueira EM, Nelson BW, Fearnside PM (2006) Volume and biomass of trees in central Amazonia: influence of irregularly shaped and hollow trunks Forest Ecology and Management 227:14-21 doi:10.1016/j.foreco.2006.02.004

Peters R, Vovides AG, Luna S, Grüters U, Berger U (2014) Changes in allometric relations of mangrove trees due to resource availability - A new mechanistic modelling approach Ecological Modelling 283:53-61 doi:10.1016/j.ecolmodel.2014.04.001

Pistorius T (2012) From RED to REDD+: the evolution of a forest-based mitigation approach for developing countries Current Opinion in Environmental Sustainability 4:638-645 doi:10.1016/j.cosust.2012.07.002

Proisy C, Couteron P, Fromard F (2007) Predicting and mapping mangrove biomass from canopy grain analysis using Fourier-based textural ordination of IKONOS images Remote Sensing of Environment 109:379-392 doi:10.1016/j.rse.2007.01.009

Pueschel P, Newnham G, Rock G, Udelhoven T, Werner W, Hill J (2013) The influence of scan mode and circle fitting on tree stem detection, stem diameter and volume extraction from terrestrial laser scans ISPRS Journal of Photogrammetry and Remote $\quad$ S7:44-56 doi:http://dx.doi.org/10.1016/j.isprsjprs.2012.12.001

Raumonen P et al. (2013) Fast Automatic Precision Tree Models from Terrestrial Laser Scanner Data Remote Sensing 5:491-520 doi:10.3390/rs5020491

Rinn F, Schweingruber F-H, Schaer E (1996) RESISTOGRAPH and $\mathrm{X}$-ray density charts of wood comparative evaluation of drill resistance profiles and X-ray density charts of different wood species Holzforschung 50:303-311

Slik JWF et al. (2013) Large trees drive forest aboveground biomass variation in moist lowland forests across the tropics Global Ecology and Biogeography 22:1261-1271

Sprugel D (1983) Correcting for bias in log-transformed allometric equations Ecology 64:209-210

Strahler AH et al. (2008) Retrieval of forest structural parameters using a ground-based lidar instrument (Echidna ${ }^{\circledR}$ ) Canadian Journal of Remote Sensing 34:S426-S440

Vanclay JK, Skovsgaard JP (1997) Evaluating forest growth models Ecological Modelling 98:1-12 doi:10.1016/S03043800(96)01932-1

Vogt J, Lin Y, Pranchai A, Frohberg P, Mehlig U, Berger U (2014) The importance of conspecific facilitation during recruitment and regeneration: A case study in degraded mangroves Basic and Applied Ecology 15:651-660 doi:http://dx.doi.org/10.1016/j.baae.2014.09.005

Yu X, Liang X, Hyyppa J, Kankare V, Vastaranta M, Holopainen $M$ (2013) Stem biomass estimation based on stem reconstruction from terrestrial laser scanning point clouds Remote Sensing Letters 4:344-353 doi:10.1080/2150704x.2012.73493 


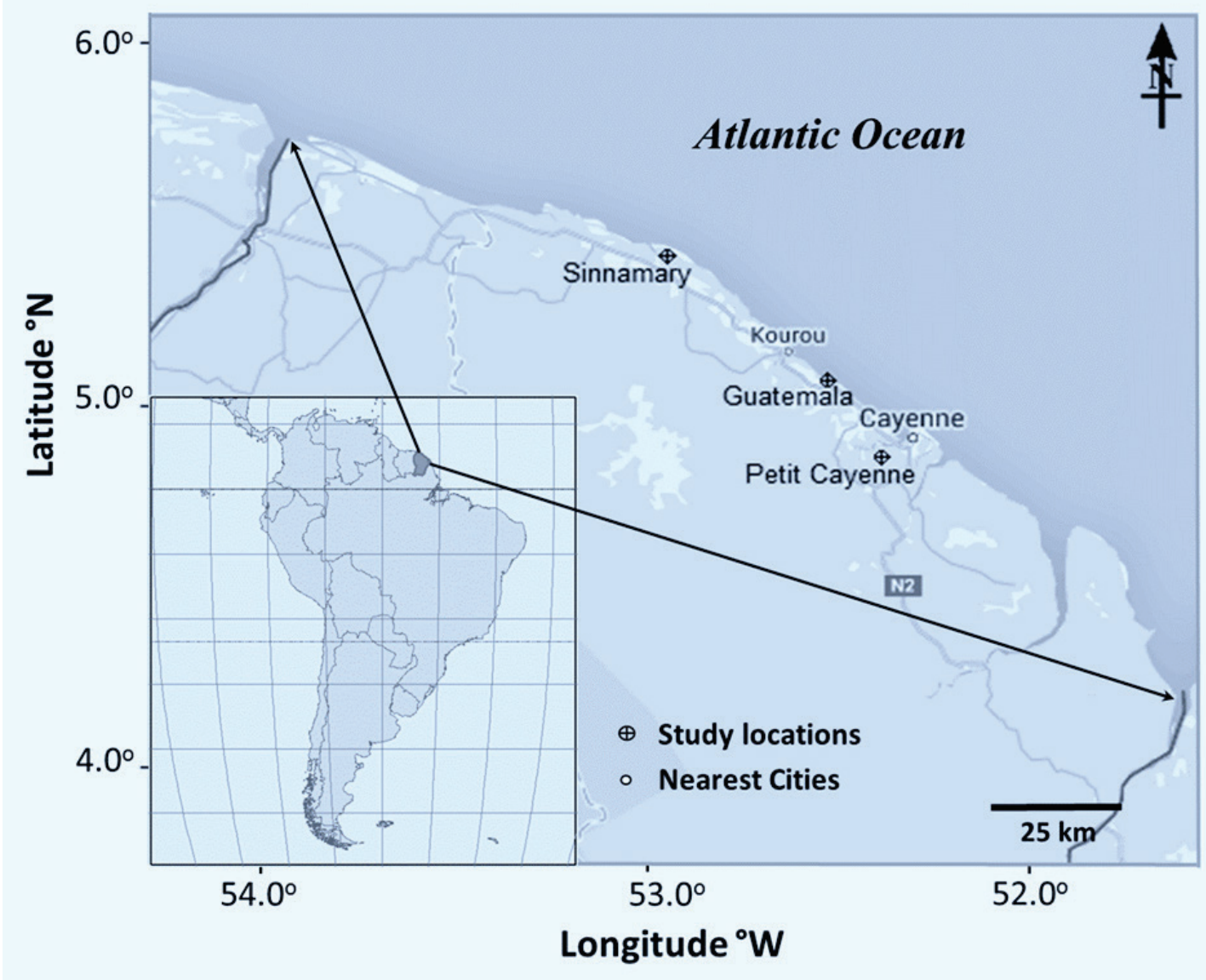

Appendix 1 Map of the coastline of French Guiana showing the locations of the study sites

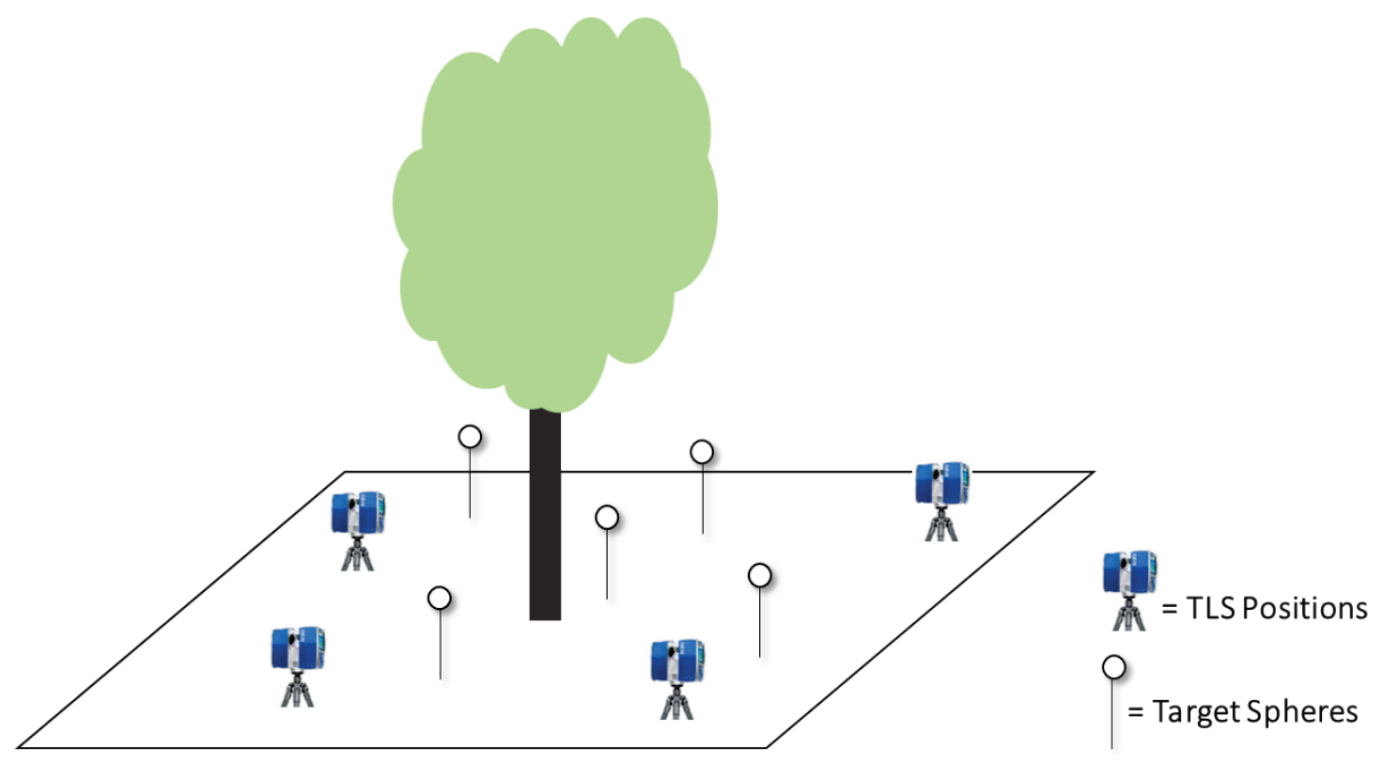

Appendix 2 Schematic representation showing the multi-scan analysis of a tree, involving four placements for the TLS instrument and five white reference spheres (target spheres mounted on metal rods) 


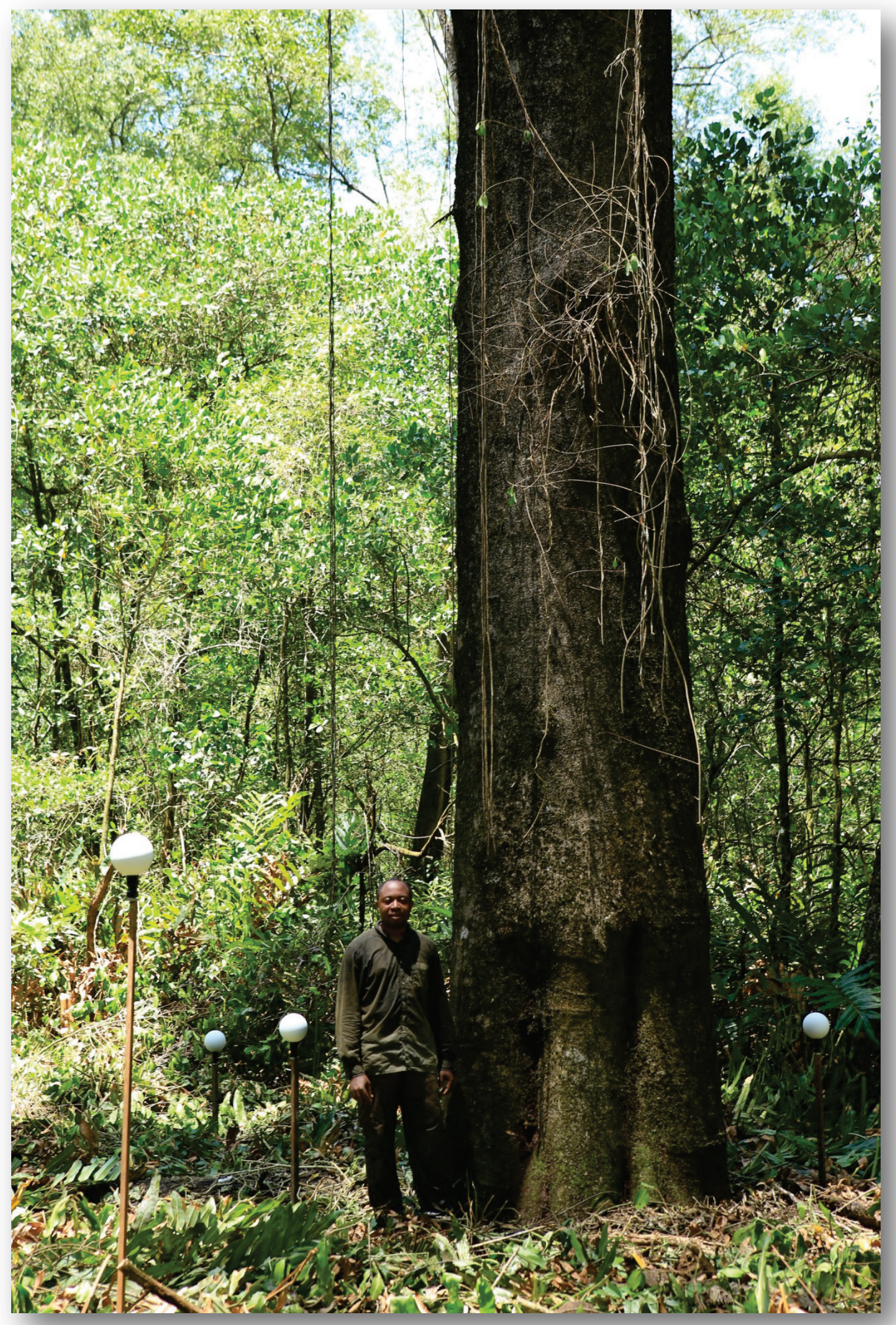

Adewole Olagoke, at the foot of a 124.5 DBH Avicennia germinans tree surrounded by white target spheres, in Petit Cayenne region, French Guiana (Photo. C. Proisy, IRD-UMR AMAP, 2014) 